\title{
Effect of temperature on lung function and symptoms in chronic obstructive pulmonary disease
}

\author{
G.C. Donaldson*, T. Seemungal**, D.J. Jeffries ${ }^{+}$, J.A. Wedzicha**
}

\begin{abstract}
Effect of temperature on lung function and symptoms in chronic obstructive pulmonary disease. G.C. Donaldson, T. Seemungal, D.J. Jeffries, J.A. Wedzicha. (C)ERS Journals Ltd 1999.

ABSTRACT: The present study investigated whether falls in environmental temperature increase morbidity from chronic obstructive pulmonary disease (COPD). Daily lung function and symptom data were collected over 12 months from 76 COPD patients living in East London and related to outdoor and bedroom temperature. Questionnaires were administered which asked primarily about the nature of night-time heating.

A fall in outdoor or bedroom temperature was associated with increased frequency of exacerbation, and decline in lung function, irrespective of whether periods of exacerbation were excluded. Forced expiratory volume in one second (FEV1) and forced vital capacity (FVC) fell markedly by a median of $45 \mathrm{~mL}(95 \%$ percentile range: $-113-229 \mathrm{~mL})$ and $74 \mathrm{~mL}(-454-991 \mathrm{~mL})$, respectively, between the warmest and coolest week of the study. The questionnaire revealed that $10 \%$ had bedrooms $<13$ C for $25 \%$ of the year, possibly because only $21 \%$ heated their bedrooms and $48 \%$ kept their windows open in November.

Temperature-related reduction in lung function, and increase in exacerbations may contribute to the high level of cold-related morbidity from chronic obstructive pulmonary disease.

Eur Respir J 1999; 13: 844-849.
\end{abstract}

Depts of *Physiology, **Respiratory Medicine and ${ }^{+}$Virology, St Bartholomew's and Royal London School of Medicine and Dentistry, Queen Mary and Westfield College, London, UK.

Correspondence: G.C. Donaldson

Dept of Physiology

Basic Medical Sciences

Queen Mary and Westfield College

Mile End Road

London, E1 4N5

UK

Fax: 441819830467

Keywords: Chronic obstructive pulmonary disease

exacerbation

temperature

Received: February 101998

Accepted after revision November 21998

Funded by the British Lung Foundation (T. Seemungal) and the Hedley Foundation.

Chronic obstructive pulmonary disease (COPD) is characterized by progressive largely irreversible airflow limitation, leading to considerable respiratory disability and mortality [1]. The frequency of exacerbation of COPD increases with worsening lung function and during the winter months. Some of these exacerbations may be due to viral and bacterial infections [2,3], but whether a cold environment is associated with exacerbation or deterioration in lung function is not known. Previous studies [2, 4, 5] have either been inconclusive, or negative, regarding a relationship between cold weather and lung function, possibly because they were of limited duration or relatively few patients were investigated, or the winter months were not examined. The relationship between temperature and exacerbation of COPD has not been examined.

Poor personal protection from indoor cold stress has been linked to increases in temperature-related mortality from all causes of respiratory disease [6]. Patients with more severe COPD may be housebound [7] and any changes in lung function may be more related to indoor rather than outdoor temperature levels, but the effects of indoor temperature have not previously been evaluated. A recent study in South-East England has reported that low daily temperatures were associated with excess deaths from respiratory disease in people $>50$ yrs of age [8].

The primary aim of this study was to determine whether cold had a deleterious effect on patients with COPD. Daily symptom and lung function data were collected over a period of 12 months in a group of patients with moderate and severe COPD living in East London, and related to mean outdoor and morning bedroom temperatures. Further analyses were made to exclude possible confounders such as humidity and windspeed. Information was also collected on bedroom heating and other habits.

\section{Methods}

\section{Lung function and symptom data}

In October 1995, 76 patients were recruited consecutively from those attending an outpatients clinic at the London Chest Hospital on the basis that they were willing to participate in a long-term study, and that they had moderate to severe COPD with a forced expiratory volume in one second (FEV1) $<70 \%$ of predicted and reversibility from baseline to inhaled salbutamol of $<15 \%$ and $200 \mathrm{~mL}$. Baseline spirometry and arterial (ear-lobe capillary) blood gas measurements were carried out [9]. Patients were asked to record, on monthly diary cards, peak expiratory flow rate (PEFR), measured indoors after their morning medication, with a Mini-Wright peak flowmeter (Clement Clarke International Ltd, Harlow, UK); indoor temperature in their bedroom on awakening using a $1{ }^{\circ} \mathrm{C}$ Thermax temperature strip (Thermographic Measurements Ltd, Burton, UK); and increase over their chronic (stable) symptoms 
during the last $24 \mathrm{~h}$ in "major" symptoms (dyspnoea, sputum purulence, sputum amount) or "minor" symptoms (nasal discharge/congestion, wheeze, sore throat, cough). Patients were seen monthly and if necessary re-taught how to complete their diary cards. Data were missed when diary cards were not filled in, lost, holidays taken outside London or patients admitted to hospital. The average number of data points was 299 per patient (range 160-363). Respiratory medication was unchanged over the year, except during exacerbation or when prescribed by a patient's general practitioner from whom it was not feasible to collect data. Exacerbations were identified by symptoms, according to defined criteria [10] of any two major symptoms or one major and one minor symptom. Twenty-seven randomly selected patients also measured FEV1 and forced vital capacity (FVC) using a hand-held spirometer (Micro Medical Ltd, Rochester, UK). All gas volumes were standardized at body temperature, ambient pressure and saturated with water (BTPS) conditions. Ethical permission was obtained from the East London and City Health Authority Ethics Committee.

\section{Questionnaire data}

In November 1996, all subjects were asked about their bedroom heating and ventilation, smoking history and pet ownership.

\section{Meteorology data}

The Meteorological Office provided three-hourly temperature, daily average windspeed and one-hourly relative humidity data recorded at the Ministry of Defence, Whitehall, London, for October 1995 to September 1996. Temperature and relative humidities were averaged to give daily mean values. No data were missing.

\section{Statistical analysis}

Lung function and symptom data. For all subjects, a regression coefficient of their FEV1 on same day outdoor temperature was calculated with allowance for serial correlation, using the method of COCHRANE and ORCUTT [11], and for annual decline in lung function. Similar calculations were made for the same 27 patients who recorded FVC and for all 76 patients who recorded PEFR. Regression coefficients were also calculated with windspeed, relative humidity or patient's bedroom temperature as the independent variable; for change in FEV1 from the previous day on change in outdoor or bedroom temperature from the previous day; and for outdoor and bedroom temperature but with data collected 7 days before and 21 days after exacerbation onset excluded to determine whether the spirometry changes were independent of exacerbation. A further analysis was made with both outdoor and indoor temperature as independent variables, the purpose of which was to determine whether outdoor temperature affected lung function independently of whether the patients lived in cold homes or not, or whether low indoor temperatures affect lung function independently of how cold it was outdoors. Logit regression was used to estimate regression coefficients for a symptom on outdoor or bedroom temperature. Symptom data from the previous day were included as additional independent variables in the regression model to correct for the problem that the data from each day were not entirely independent of that of the previous day. Tests showed that the distributions of the coefficients were generally skewed or with kurtosis; thus median values are reported and tests for significance from zero made using the Wilcoxon sign-ranked test. The correlation between the regression coefficients of FEV1 on outdoor temperature and per cent reversibility to salbutamol was also calculated. Bubble-plots of symptoms against temperature were made by determining the proportion of the group reporting a symptom on a given day and then binning these into $1{ }^{\circ} \mathrm{C}$ intervals (the area of the bubble

Table 1. - Median regression coefficients (MRC) and 2.5-97.5 percentile ranges of spirometry on outdoor and bedroom temperature (with and without exacerbations), relative humidity and windspeed

\begin{tabular}{|c|c|c|}
\hline & Including exacerbations & Excluding exacerbations \\
\hline \multicolumn{3}{|l|}{ On outdoor temperature } \\
\hline $\mathrm{FEV} 1 \mathrm{~mL} \cdot{ }^{\circ} \mathrm{C}^{-1}$ & $2.20(-5.5-11.2)^{* *}$ & $1.27(-2.7-11.3)^{* *}$ \\
\hline $\mathrm{FVC} \mathrm{mL} \cdot{ }^{\circ} \mathrm{C}^{-1}$ & $3.64(-22.4-48.6)^{* *}$ & $3.69(-8.5-48.6)^{*}$ \\
\hline PEFR L $\cdot \min ^{-1} \cdot{ }^{\circ} \mathrm{C}^{-1}$ & $0.12(-0.97-1.67)^{* *}$ & $0.18(-1.13-1.91)^{*}$ \\
\hline$\Delta \mathrm{FEV} 1 \mathrm{~mL} \cdot{ }^{\circ} \mathrm{C}^{-1}$ & $1.13(-8.0-7.8)^{* *}$ & $0.83(-11.5-7.53)^{*}$ \\
\hline \multicolumn{3}{|l|}{ On bedroom temperature } \\
\hline $\mathrm{FEV} 1 \mathrm{~mL} \cdot{ }^{\circ} \mathrm{C}^{-1}$ & $3.03(-8.9-52.7)^{* *}$ & $2.92(-10.3-21.8)^{*}$ \\
\hline $\mathrm{FVC} \mathrm{mL} \cdot{ }^{\circ} \mathrm{C}^{-1}$ & $10.90(-36.6-91.1)^{* *}$ & $10.00(-27.4-91.1)^{*}$ \\
\hline PEFR L $\cdot \min ^{-1} \cdot{ }^{\circ} \mathrm{C}^{-1}$ & $0.41(-1.55-7.50)^{* * *}$ & $0.61(-2.65-7.84)^{* * *}$ \\
\hline$\Delta \mathrm{FEV} 1 \mathrm{~mL} \cdot{ }^{\circ} \mathrm{C}^{-1}$ & $3.08(-13.3-38.3)^{* *}$ & $3.04(-13.0-18.0)$ \\
\hline \multicolumn{3}{|l|}{ On relative humidity $\%$} \\
\hline FEV $1 \mathrm{~mL} \cdot \%^{-1}$ & & \\
\hline $\mathrm{FVC} \mathrm{mL} \cdot \%^{-1}$ & & \\
\hline PEFR L. $\min ^{-1} \cdot \%{ }^{-1}$ & & \\
\hline \multicolumn{3}{|l|}{ On windspeed $\mathrm{m} \cdot \mathrm{s}^{-1}$} \\
\hline $\mathrm{FEV} 1 \mathrm{~mL} \cdot \mathrm{m}^{-1} \cdot \mathrm{s}^{-1}$ & & \\
\hline $\mathrm{FVC} \mathrm{mL} \cdot \mathrm{m}^{-1} \cdot \mathrm{s}^{-1}$ & & \\
\hline PEFR L $\cdot \mathrm{m}^{-1} \cdot \mathrm{s}^{-1}$ & & \\
\hline
\end{tabular}

FEV1: forced expiratory volume in one second; FVC: forced vital capacity; PEFR: peak expiratory flow rate; $\triangle$ FEV1: 1-day change in FEV1 on 1-day change in temperature. ${ }^{*}: \mathrm{p}<0.05 ; * *: \mathrm{p}<0.01 ; * * *: \mathrm{p}<0.001$. 

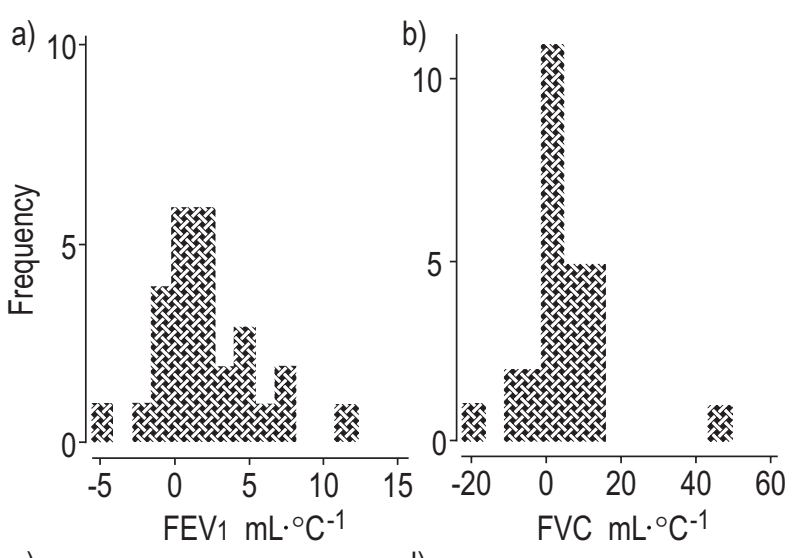

c)

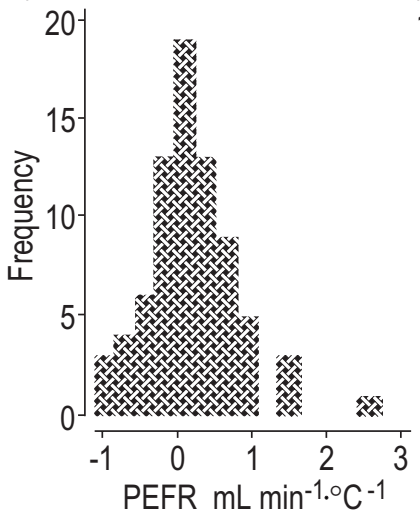

)

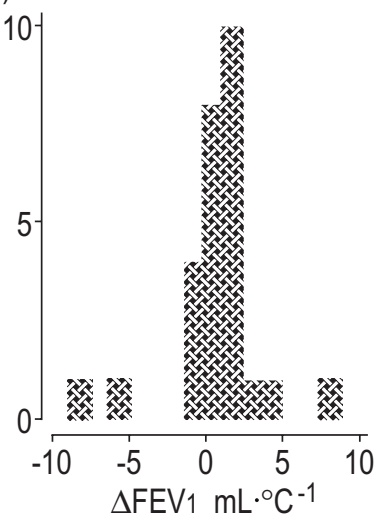

Fig. 1. - Histograms of regression coefficients of a) forced expiratory volume in one second (FEV1), b) forced vital capacity (FVC) and c) peak expiratory flow rate (PEFR) on outdoor temperature, and d) 1-day change in FEV1 on 1-day change in outdoor temperature $(\triangle \mathrm{FEV} 1)$; data during periods of exacerbations included.

is a measure of the number of days within the interval). Anthropomorphic and questionnaire results are reported as means and SD.

\section{Results}

The group of 76 COPD patients comprised 56 males and 20 females with mean age $68 \pm 8$ yrs. On entering the study they had a mean FEV1 of $1.06 \pm 0.43 \mathrm{~L}, \mathrm{FVC} 2.49 \pm 0.8 \mathrm{~L}$, predicted FEV1 $40.8 \pm 19.4 \%$ reversibility to salbutamol $6.2 \pm 8.9 \%$, PEFR $224 \pm 78 \mathrm{~L} \cdot \mathrm{min}^{-1}$ and arterial oxygen tension $\left(P \mathrm{a}, \mathrm{O}_{2}\right) 8.83 \pm 1.06 \mathrm{kPa}$. Ninety-five per cent had smoked and $35 \%$ currently smoked, $3 \%$ still worked and $29 \%$ owned either a dog, cat or bird. The subset in whom daily FEV1 and FVC were recorded comprised 24 males and three females, mean age $65 \pm 1.2$ yrs, FEV1 $1.11 \pm 0.43 \mathrm{~L}$, FVC $2.52 \pm 0.65 \mathrm{~L}$, predicted FEV1 $37.6 \pm 16.6 \%$, reversibility to salbutamol $8.2 \pm 9.0 \%$, PEFR $259 \pm 69 \mathrm{~L} \cdot \mathrm{min}^{-1}$, and $\mathrm{Pa} \mathrm{O}_{2} \quad 8.71 \pm 1.20 \mathrm{kPa}$. This subset was not significantly different in any of these from the main group.

Table 1 shows that FEV1, FVC and PEFR were positively and significantly related to either outdoor or bedroom temperature, as was 1-day change in FEV1 on 1-day change in outdoor or bedroom temperature (see figure 1 for distributions). No systematic alinearities in these relationships with temperature were seen; an example is shown in figure $2 \mathrm{a}$. The warmest and coldest weeks of the
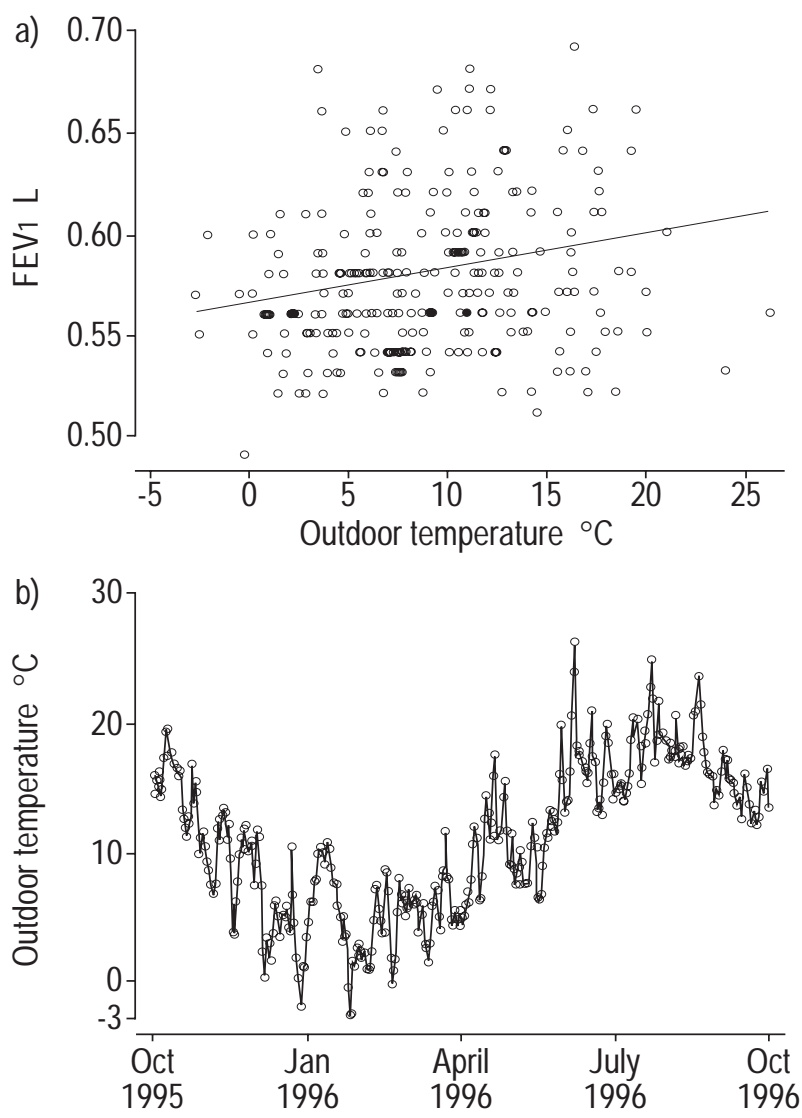

Fig. 2. - a) Forced expiratory volume in one second (FEV1) on outdoor temperature, an example from one subject. b) Outdoor temperature in Central London; $1 / 10 / 1995$ to $31 / 9 / 1996$.

year had mean temperatures of 21.1 and $0.7^{\circ} \mathrm{C}$, respectively (fig. 2b), thus the typical temperature-related change over the year in PEFR would have been $2.4 \mathrm{~L} \cdot \mathrm{min}^{-1}(95 \%$ percentile range $\left.-20.4-34.1 \mathrm{~L} \cdot \mathrm{min}^{-1}\right)$; in FEV1 $45 \mathrm{~mL}$ $(-113-229 \mathrm{~mL})$ and in FVC $74 \mathrm{~mL}(-454-991 \mathrm{~mL})$. No correlation was found between the regression coefficients of FEV1 on outdoor temperature and reversibility to inhaled salbutamol measured at the start of the study $(\mathrm{r}=0.23, \mathrm{p}=0.26)$. Table 1 also shows median regression coefficients and their 2.5-97.5 percentile range obtained when data collected during exacerbation were excluded, and lung function remained significantly and positively associated with outdoor and bedroom temperature. The number of exacerbations averaged $2.5 \pm 1.9$ for the whole and 3.0 \pm 2.0 for the subset. One-day change in FEV1 was related to 1-day change in outdoor temperature $(\mathrm{p}=0.048)$ but not quite significantly to bedroom temperature $(\mathrm{p}=$ 0.055). FEV1, FVC and PEFR were generally not related to either relative humidity or windspeed, except FVC negatively to relative humidity and PEFR positively to windspeed. Bedroom temperature was highly related to outdoor temperature (median coefficient $=0.113^{\circ} \mathrm{C} \cdot{ }^{\circ} \mathrm{C}^{-1}$; $95 \%$ range $-0.0058-0.3862 ; \mathrm{p}<0.001)$. By determining the $25 \%$ quartile it was found that for $25 \%$ of the year, bedroom temperatures in the homes of $10 \%$ of the patients were $\leq 13^{\circ} \mathrm{C}$.

FEV1 was positively associated with outdoor temperature (median coefficient $1.5 \mathrm{~mL} \cdot{ }^{\circ} \mathrm{C}^{-1} ; 95 \%$ percentile range 
Table 2. - Median logit regression coefficients (MLRC) and quartile range of symptoms and exacerbation on outdoor and bedroom temperature

\begin{tabular}{|c|c|c|c|c|c|c|}
\hline & \multicolumn{3}{|c|}{ On outdoor temperature } & \multicolumn{3}{|c|}{ On bedroom temperature } \\
\hline & MLRC & Quartile range & $\mathrm{n}$ & MLRC & Quartile range & $\mathrm{n}$ \\
\hline Shortness of breath & 0.009 & $(-0.055-0.043)$ & 58 & 0.019 & $(-0.187-0.095)$ & 57 \\
\hline Sputum colour & -0.005 & $(-0.085-0.054)$ & 42 & -0.095 & $(-0.243-0.107)$ & 41 \\
\hline Sputum amount & -0.004 & $(-0.101-0.600)$ & 50 & -0.073 & $(-0.245-0.107)^{*}$ & 50 \\
\hline Wheeze & -0.009 & $(-0.104-0.076)$ & 48 & -0.007 & $(-0.197-0.164)$ & 22 \\
\hline Sore throat & -0.053 & $(-0.138-0.045)$ & 21 & -0.053 & $(-0.362-0.135)$ & 22 \\
\hline Cough & -0.014 & $(-0.127-0.088)$ & 40 & -0.065 & $(-0.283-0.121)$ & 39 \\
\hline Nasal congestion & -0.101 & $(-0.183-0.015)^{* * *}$ & 47 & -0.187 & $(-0.458-0.167) * * *$ & 47 \\
\hline Exacerbation & -0.026 & $(-0.116-0.309)^{*}$ & 65 & -0.071 & $(-0.285-0.147)$ & 62 \\
\hline
\end{tabular}

$\mathrm{n}$ : number of patients with symptom; *: $\mathrm{p}<0.05 ; * * *: \mathrm{p}<0.001$.

$-5.9-8.1$; significance from zero, $\mathrm{p}=0.02)$ independently of bedroom temperature $\left(1.10 \mathrm{~mL} \cdot{ }^{\circ} \mathrm{C}^{-1} ; 95 \%\right.$ range, -13.7 , $56.6 ; \mathrm{p}=0.08)$. PEFR was positively associated with bedroom temperature $\left(0.41 \mathrm{~L} \cdot \min \cdot{ }^{\circ} \mathrm{C}^{-1} ;-2.14,6.51 ; \mathrm{p}<0.001\right)$, independently of outdoor temperature $\left(0.09 \mathrm{~L} \cdot \mathrm{min} \cdot{ }^{\circ} \mathrm{C}^{-1}\right.$; $-1.41,1.21 ; \mathrm{p}=0.18)$. FVC was not significantly related to either, coefficients $7.69 \mathrm{~mL} \cdot{ }^{\circ} \mathrm{C}^{-1}$ outdoors; $-20.9,51.1 ; \mathrm{p}=$ 0.06 and $3.56 \mathrm{~mL} \cdot{ }^{\circ} \mathrm{C}^{-1}$ bedroom; -20.9, 74.8; $\mathrm{p}=0.09$.

Figure 3 shows the proportion of the group reporting an increase in symptoms and diagnosis of exacerbation, plotted against outdoor temperature. There was considerable scatter with a tendency for all variables except shortness of breath to increase in cold weather. Table 2 gives median logistic regression coefficients of symptoms on outdoor and bedroom temperature (a negative coefficient indicating an increase in cold conditions). The symptoms of nasal congestion and exacerbation were significantly related to outdoor temperature, and those of nasal congestion and increased sputum volume to bedroom temperature. Exacerbation against bedroom temperature was almost significant $(\mathrm{p}=0.052)$.

\section{Home heating habits}

Sixty-nine of the 76 COPD patients responded to the questionnaire, and of these 51 had central, electrical or gas heating appliances in their bedrooms. However, only 14 patients used heating at night. Thirty-three patients kept their bedroom windows open and 55 spent on average $20.5 \pm 43 \mathrm{~min}$ out of bed, at night.

\section{Discussion}

The main finding from this study is that falls in environmental temperatures are associated with a reduction in lung function in patients with COPD. FEV1 fell typically by $44.9 \mathrm{~mL}$ (at $2.20 \mathrm{~mL} \cdot{ }^{\circ} \mathrm{C}^{-1}$ outdoors) and $\mathrm{FVC}$ by $74.2 \mathrm{~mL}$ (at $3.64 \mathrm{~mL} \cdot{ }^{\circ} \mathrm{C}^{-1}$ outdoors) between the warmest and coolest weeks in the 12 months studied. These changes were larger than for PEFR $\left(2.4 \mathrm{~L} \cdot \mathrm{min}^{-1}\right.$ over the same temperature range), possibly because they reflect changes in both small and large airway, unlike PEFR which is mainly determined by large airway calibre. Although the falls in lung function are relatively small, their importance is that they may be sufficient to compromise patients with COPD who already have marked airflow obstruction (or may make them more susceptible to infections). This finding is contrary to previous studies $[2,4,5]$ possibly because a greater number of COPD patients were closely monitored over a longer period in this study. The deterioration in lung function could not easily be otherwise explained by changes in relative humidity or windspeed, as there were no consistent relationships between these and lung function. Another possible alternative explanation is greater atmospheric pollution in the winter. However, a preliminary analysis of spirometry data from this over the first 6 months and of ambient air pollution at that time showed little relationship, possibly because pollution levels in London were not high enough to produce any response (mean ozone $9.4 \pm 6.3$ parts per billion (ppb); nitric oxide $44.5 \pm 41.4 \mathrm{ppb}$, sulphur dioxide $7.6 \pm 5.8 \mathrm{ppb}$; during the study in Bloomsbury Square, Central London).

It may have been that ambient temperature had an important effect on the measuring instruments. MiniWright flow meters have been found to underestimate PEFR by $0.8 \%$ if the device is cooled in a refrigerator from 37 to $10^{\circ} \mathrm{C}$ and Micro-Medical turbine spirometers have also been found to under-read by $1 \%$ after 3 weeks at $-4^{\circ} \mathrm{C}$ compared to measurements at $25^{\circ} \mathrm{C}[12,13]$. Errors due to this would, however, be very small, as the median room temperature at which the lung function measurements were made varied for subjects by only $2.3^{\circ} \mathrm{C}$ between the warmest and coolest weeks in this study. In addition, the smallest median temperature-related change observed, $0.18 \% \cdot{ }^{\circ} \mathrm{C}^{-1}$ for PEFR on indoors temperature (baseline $244 \mathrm{~L} \cdot \mathrm{min}^{-1}$ ) was six-times greater than the reported instrumentation error of $0.03 \% \cdot{ }^{\circ} \mathrm{C}^{-1}$. Micro-Medical spirometers have excellent long-term reproducibility [14]. The reductions in the spirometric readings also could not be attributed solely to exacerbations of COPD, even though these were more frequent in cold conditions, as the relationship between lung function and temperature remained after excluding data collected over a four-week period during exacerbation. The changes were also not due to a seasonal effect, such as diet, as they remained if any seasonal effect was removed by examining 1-day changes in spirometry and temperature [15]. Thus, it appears that temperature has an effect on lung function in patients with COPD, and these changes should be taken into account when interpreting long-term studies.

The reduction in lung function may be caused by increased airway inflammation in winter. Recent work has shown that exacerbations of asthma are largely precipitated by viral infections, especially with rhinovirus $[16,17]$, and 

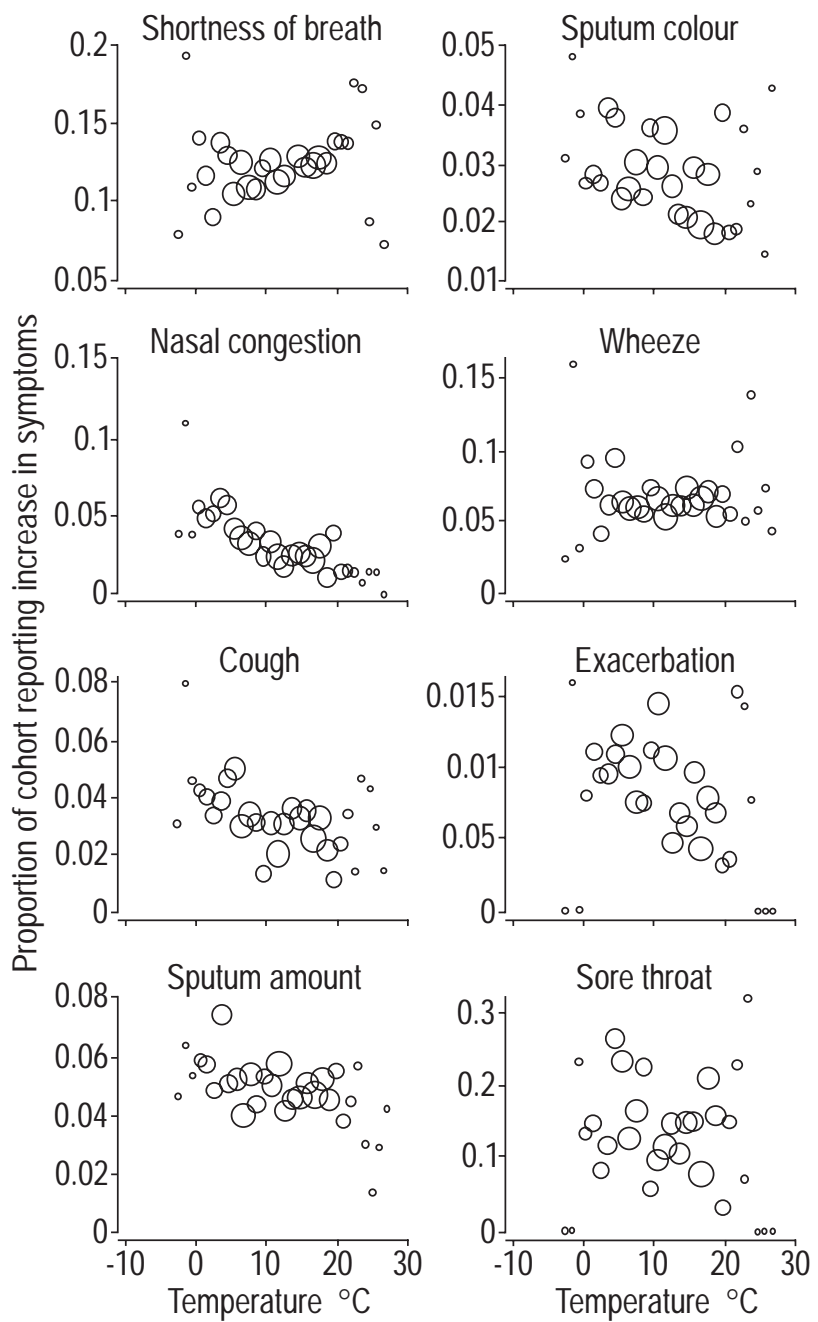

Fig. 3. - Bubble plots of respiratory symptoms against same day outdoor temperature; size of bubble indicates number of days within each $1^{\circ} \mathrm{C}$ interval.

it is likely that viruses are also important in increasing airway inflammation in COPD in winter. Upper respiratory tract infection with rhinovirus, which is commoner during the winter season, has been shown to cause lower airway inflammation in asthma [18, 19]. Similarly, inflammatory changes in COPD could contribute to a persistent fall in FEV1, without the presence of a symptomatic exacerbation. In the present study, it was found that common cold symptoms, such as nasal congestion, were also related to the fall in temperature in winter. Adenoviral deoxyribonucleic acid has been detected in airways of patients with COPD and reactivation of latent viral infection with cold temperature could also induce airway inflammatory changes [20]. Patients with COPD also show increased levels of the cytokines tumour necrosis factor- $\alpha$ and interleukin-8 in sputum, which are involved in neutrophil chemoattraction and activation [21]. Low ambient temperatures may act directly through cytokine activation to induce airway inflammatory changes. Mechanical factors may also be implicated as cold temperatures will cause increased peripheral vasoconstriction and shunt blood centrally [22] and thus reduce lung capacity. Inhalation of cold air can cause post-exertional bronchoconstriction in asth- matics, although this effect may be due to drying of the airways $[23,24]$. Patients with COPD have a largely fixed airflow obstruction, with relatively little daily variability and thus it is unlikely that they will show significant bronchoconstriction as a result of the direct effect of cold on airways. This is supported by the absence of any abrupt changes in the linearity of relationships between the spirometry and temperature, and by the absence of any relation between the fall in FEV1 with temperature and reversibility to inhaled salbutamol.

This is the first study to investigate the effect of indoor temperature in patients with COPD, whose disability makes them more likely to be housebound. Morning bedroom temperature was measured on rising to obtain the lowest value experienced during the night which was practical for patients to record. The study clearly showed that low bedroom temperatures were associated with reduced lung function, although it was not possible to show independent and significant effects of both outdoor and indoor temperature, perhaps owing to the variance-inflation produced by their co-linearity. However, FEV1 was significantly associated with outdoor temperature whilst independent of bedroom temperature, and PEFR was significantly associated with bedroom temperature, independently of outdoor temperature; and all were positive. It seems reasonable therefore to assume that low temperatures, either outdoors or indoors, will be associated with reduced lung function. A large proportion of the study COPD patients were found not to heat their bedrooms and kept their windows open at night, which would explain why a proportion had markedly cold bedrooms. Further studies would, however, be necessary to show that better protection from cold outdoors (especially the wearing of hats and scarfs [6]), improved bedroom heating, and the closure of windows at night would make an improvement in the health of COPD patients, although this is suggested by the results of the present study.

This study has demonstrated that a cold environment, whether during outdoor excursion or indoors, was associated with reduction in spirometric values. The interaction of reduced lung function and exacerbation during cold weather may contribute to the high cold-related morbidity and mortality in chronic obstructive pulmonary disease patients who are already suffering from chronic respiratory disability and increased susceptibility to respiratory failure.

Acknowledgements. The authors would like to thank E. Paul and J. Peacock (St Georges Hospital Medical School) for their statistical advice, C. Evans for her help in collecting the lung function data, and the Meteorological office for climate data.

\section{References}

1. Fletcher EC, Peto R. The natural history of chronic airflow obstruction. Br Med $J$ 1977; I: 1645-1648.

2. McHardy VU, Inglis JM, Calder MA, Crofton JW. A study of infective and other factors in exacerbations of chronic bronchitis. Br J Dis Chest 1980; 74: 228-238.

3. Tager I, Speizer FE. Role of infection in chronic bronchitis. N Engl J Med 1975; 292: 563-571. 
4. Mann M, Patel K, Reardon JZ, Goldstein M, Godar TJ, ZuWallack RL. The influence of spring and summer New England meterological conditions on the respiratory status of patients with chronic lung disease. Chest 1993; 103: 1369-1374.

5. Spicer WS, Reinke WA, Kerr HD. Effects of environment upon respiratory function. Arch Environ Health 1966; 13: 753-762.

6. Keatinge WR, Donaldson GC, Bucher K, et al. Coldexposure associated with winter mortalities from ischaemic heart, cerebrovascular, and respiratory disease, and all-causes, in warm and cold regions of Europe. Lancet 1997; 349: 1341-1346.

7. Restrick LJ, Paul EA, Braid GM, Cullinan P, MooreGillon L, Wedzicha JA. Assessment and follow-up of patients prescribed long-term oxygen therapy. Thorax 1993; 48: 708-713.

8. Donaldson GC, Keatinge WR. Early increases in ischaemic heart disease mortality dissociated from, and later changes associated with, respiratory disease, after cold weather in south-east England. J Epidem Commun Health 1997; 51: 643-648.

9. Pitkin AD, Roberts CM, Wedzicha JA. Arterialised ear lobe blood gas analysis: an underused technique. Thorax 1994; 49: 364-366.

10. Anthonisen NR, Manfreda J, Warren CP, Heshford EW, Harding GKM, Nelson NA. Antibiotic therapy in exacerbation of chronic obstructive pulmonary disease. Ann Intern Med 1987; 106: 196-204

11. Cochrane D, Orcutt GH. Application of least squares regression to relationships containing autocorrelation error terms. J Am Stat Assoc 1949; 4: 32-61.

12. Pedersen OF, Miller MR, Sigsgaard T, Tidley M, Harding RM. Portable peak flow meters: physical characteristics, influence of temperature, altitude, and humidity. Eur Respir J 1994; 4: 991-997.

13. Pollard AJ, Mason NP, Barry PW, et al. Effect of altitude on spirometric parameters and the performance of peak flow meters. Thorax 1996; 51: 175-178.

14. Dirksen A, Madsen F, Pedersen OF, Vedel AM, Kok-
Jensen A. Long term performance of a hand held spirometer. Thorax 1996; 51: 973-976.

15. Diggle PJ. Time-series: A Biostatistical Introduction. Oxford, Claridon Press, 1990.

16. Nicholson KG, Kent J, Ireland DC. Respiratory viruses and exacerbations of asthma in adults. Br Med $J$ 1993; 307: 982-986.

17. Johnston SL, Pattemore PK, Sanderson G, et al. Community study of role of viral infections in exacerbations of asthma in 9-11 year old children. Br Med $J$ 1995; 310: $1225-1229$.

18. Fraenkel DJ, Bardin PG, Sanderson G, Lampe F, Johnston SL, Holgate ST. Lower airways inflammation during rhinovirus colds in normal and in asthmatic subjects. $A m J$ Respir Crit Care Med 1995; 151: 879-886.

19. Cheung D, Dick EC, Timmers MK, de Klerk EP, Spaan WJ, Sterk P. Rhinovirus inhalation causes long-lasting excessive airway narrowing in response to methacholine in asthmatic subjects in vivo. Am J Respir Crit Care Med 1995; 152: 1490-1496.

20. Matsuse T, Hayashi S, Kuwano K, Keunecke H, Jefferies W, Hogg JC. Latent adenoviral infection in the pathogenesis of chronic airway obstruction. Am Rev Respir Dis 1992; 146: 177-184.

21. Keatings VM, Collins PD, Scott DM, Barnes PJ. Differences in interleukin-8 and tumour necrosis factor in induced sputum from patients with chronic obstructive pulmonary disease and asthma. Am J Respir Crit Care Med 1996; 153: 530-534.

22. Wilmshurst PT, Crowther A, Nuri M, Webb-Peploe MM. Cold-induced pulmonary oedema in scuba divers and swimmers and subsequent development of hypertension. Lancet 1989; 1: 62-65.

23. Strauss RH, McFadden ER, Ingram RH, Deal EC, Jaeger JJ. Enhancement of exercise-induced asthma by cold air breathing. N Engl J Med 1977; 297: 743-747.

24. Strauss RH, McFadden ER, Ingram RH, Deal EC, Jaeger JJ, Stearns D. Influence of heat and humidity on the airway obstruction induced by exercise in asthma. J Clin Invest 1978; 61: 433-440. 